\title{
Comparison of Fasting and Non-fasting Lipid Profile in Young Healthy Adults
}

\author{
Satish Dipankar ${ }^{1, *}$, Shankar Pawar ${ }^{2}$
}

\section{Satish Dipankar,*, Shakar Pawar $^{2}$}

${ }^{1}$ Department of Physiology, All India Institute of Medical Sciences, Patna, Bihar, INDIA.

${ }^{2}$ Department of Biochemistry, Government Medical College, Rajnandgaon, Chhattisgarh, INDIA.

\section{Correspondence}

\section{Dr. Satish Dipankar}

Associate Professor, Department of Physiology, All India Institute of Medical Sciences, Patna, Bihar-801507, INDIA.

Email: drsatishdipankar@aiimspatna. org

\section{History}

- Submission Date: 20-10-2018;

- Review completed: 12-01-2019;

- Accepted Date: 29-01-2019.

DOI : 10.5530/ijcep.2019.6.1.3

\section{Copyright}

(C) 2019 Phcog.Net. This is an openaccess article distributed under the terms of the Creative Commons Attribution 4.0 International license.

\begin{abstract}
Background and Aim: It is necessary to find out whether fasting blood samples are must for lipid profile determination. Aim of this study to find out is there any difference between fasting and non-fasting lipid profile in young healthy adults. Methods: This study was done on 100 MBBS students of medical college. Lipid profile was done in these healthy young adults for fasting and postprandial statuses. Results: The lipid profile parameters were compared in both the groups of fasting and postprandial statuses. In fasting group, the mean total cholesterol level was $192.1 \mathrm{mg} / \mathrm{dl}$ and mean postprandial total cholesterol level was $194.98 \mathrm{mg} / \mathrm{dl}(P=0.0407)$. The mean fasting serum triglyceride level was $121.16 \mathrm{mg} / \mathrm{dl}$ and mean postprandial serum triglyceride level was $126.18 \mathrm{mg} / \mathrm{dl}(P=0.0001)$. The mean fasting high density lipoprotein (HDL) level was $45.08 \mathrm{mg} / \mathrm{dl}$ and mean postprandial HDL was $43.84 \mathrm{mg} / \mathrm{dl}(P=0.0656)$. The mean fasting serum VLDL level was $24.23 \mathrm{mg} / \mathrm{dl}$ and mean postprandial VLDL level was $25.24 \mathrm{mg} / \mathrm{dl}(P=0.0001)$. The mean fasting LDL was $122.8 \mathrm{mg} / \mathrm{dl}$ and mean postprandial LDL was $125.9 \mathrm{mg} / \mathrm{dl}(P=0.0416)$. Conclusion: Finally, from this study we found that there is no significant clinical difference between fasting and non-fasting levels of total cholesterol, HDL, LDL, VLDL and TG. Thus, for estimation of lipid profile we can use the blood samples at any time or irrespective of mealtime.
\end{abstract}

Key words: Lipid profile, Fasting, Non-fasting, Total-cholesterol (TC), High density lipoproteincholesterol (HDL), Low density lipoprotein-cholesterol (LDL), Very low-density lipoproteincholesterol (VLDL), Triglycerides (TG).

\section{INTRODUCTION}

In cardiology, diabetology, thyroid clinics, etc. estimation of lipid profile is now a days common and frequently done test. Serum lipid profile has now become almost a routine test. It is usually done in fasting state due to certain alterations in postprandial triglyceride and subsequent calculated LDL values in non-fasting serum sample but in few recent studies it has been seen that there is no much difference between the values of fasting lipid profile and non-fasting lipid profile. ${ }^{[1]}$ It is difficult to get fasting blood samples of diabetics and children. In such conditions why to put burden on patients to be overnight fasting and why to put burden on the laboratory to collect early morning blood samples? In recent studies most daytime lipid concentrations changed only slightly therefore non-fasting samples could be used for routine lipid tests. However, in cases of abnormal postprandial triglyceride concentrations, dietary factors and fasting time should be considered when interpreting the results. It is important to establish an optimal cutpoint for nonfasting triglycerides to be used for the reporting of abnormal lipid profiles. Recently several societies' guidelines and statements in Denmark, the United Kingdom, Europe, Canada, Brazil and the United States endorse nonfasting lipid profiles. ${ }^{[2]}$ as previously required for lipid profiles, normally only occurs a few hours before breakfast. By contrast, the nonfasting state predominates most of a $24 \mathrm{~h} c y$ cle and better captures atherogenic lipoprotein levels. Plasma contains atherogenic lipoproteins of hepatic origin in the fasting state and additionally those of intestinal origin in the nonfasting state. Maximal mean changes for random, nonfasting versus fasting levels are $+26 \mathrm{mg} / \mathrm{dl}$ for triglycerides, $-8 \mathrm{mg} / \mathrm{dl}$ for total cholesterol, $-8 \mathrm{mg} / \mathrm{dl}$ for low-density lipoprotein cholesterol, $+8 \mathrm{mg} / \mathrm{dl}$ for remnant cholesterol, and $-8 \mathrm{mg} / \mathrm{dl}$ for non-high-density lipoprotein cholesterol; lipoprotein (a).

In this study, we will discuss the difference between the lipid parameters (TC, TG, HDL and LDL) in both fasting and postprandial statuses.

\section{MATERIALS AND METHODS}

\section{Materials}

Study group: 100 healthy young adults.

Inclusion Criteria: Healthy young adults between the age group of 18 to 25years having BMI between 18.5 to 25 .

Exclusion Criteria: Young adults suffering from any disease. Pregnant and breast-feeding mothers, nonalcoholics, nonsmokers. 
Study material: Blood samples.

\section{Methods}

This study was performed on 100 healthy young adults without dyslipidemia. Lipid profile was determined for fasting and postprandial statuses. Two blood samples-one fasting after $10 \mathrm{~h}$ overnight fast and another after two h of breakfast were drawn and subjected to testing for lipid profile. Lipid profile was estimated by enzymatic kit method.

1. Estimation of Total Cholesterol in serum (enzymatic method: cholesterol oxidase/ peroxidase): the assay was carried out by using A25 bio system auto analyzer. Reference range: Upto $200 \mathrm{mg} / \mathrm{dl}-$ desirable, 200-239 mg/dl-borderline high and > $240 \mathrm{mg} / \mathrm{dl}-$ High.

2. Estimation of serum Triglycerides (Enzymatic method glycerol phosphate/ peroxidase): the assay was carried out using A25 bio system auto analyzer. Reference range: Upto $150 \mathrm{mg} / \mathrm{dl}$ - Normal, 150-199 mg/dl-Borderline high, 240-249 mg/dl - High and > 500 $\mathrm{mg} / \mathrm{dl}$ - Very high.

3. Estimation of serum High Density Lipoprotein-Cholesterol (direct detergent method): the assay was carried out by using A25 bio system auto analyzer. Reference range: Upto $35 \mathrm{mg} / \mathrm{dl}$ - High risk, $>60 \mathrm{mg} / \mathrm{dl}-$ Low risk.

4. Estimation of serum Very Low-Density Lipoprotein: VLDL Cholesterol is calculated by Friedewald equation (Triglycerides/5). Reference range: $5-40 \mathrm{mg} / \mathrm{dl}$ and $>40 \mathrm{mg} / \mathrm{dl}$ high

5. Estimation of serum Low Density Lipoprotein-Cholesterol. Serum LDL-Cholesterol is calculated by Friedewald equation LDL-cholesterol $=$ Total cholesterol $-[$ HDL-C $+($ triglycerides $/ 5)]$. Serum LDL cholesterol was estimated by direct method when TG values were > $400 \mathrm{mg} / \mathrm{dl}$.

\section{Statistical analysis of data}

Statistical analysis of the data was performed using Graph bar diagram and Microsoft Excel 2007. For every test of $p$ value $\leq 0.05$ was considered as statistically significant.

\section{RESULTS}

The lipid profile parameters in both groups in fasting and postprandial statuses were compared. In fasting group, the mean fasting serum total cholesterol level was $192.1 \mathrm{mg} / \mathrm{dl}$ and in postprandial group, mean serum total cholesterol level was $194.98 \mathrm{mg} / \mathrm{dl}(P=0.0407)$. In fasting group, the mean fasting serum triglyceride level was $121.16 \mathrm{mg} / \mathrm{dl}$ and in postprandial group, mean serum triglyceride level was $126.18 \mathrm{mg} / \mathrm{dl}(P=0.0001)$. The mean fasting High Density Lipoprotein (HDL) level was $45.08 \mathrm{mg} /$ $\mathrm{dl}$ and mean postprandial HDL was $43.84 \mathrm{mg} / \mathrm{dl}(P=0.0656)$. The mean fasting serum VLDL level was $24.23 \mathrm{mg} / \mathrm{dl}$ and mean postprandial VLDL level was $25.24 \mathrm{mg} / \mathrm{dl}(P=0.0001)$. The mean fasting LDL was $122.8 \mathrm{mg} / \mathrm{dl}$ and mean postprandial LDL was $125.9 \mathrm{mg} / \mathrm{dl}(P=0.0416)$.

\section{DISCUSSION}

To save the time and expenses for special instrument required for LDL-C estimation we used universally accepted Friedewald equation we used all values of lipid profile in $\mathrm{mg} / \mathrm{dl}$, study population is healthy young adults and TG values are less than $400 \mathrm{mg} / \mathrm{dl}$.

In our study, on comparison of lipid profile parameters in both fasting and postprandial statuses, the mean level of Total cholesterol (192.1 vs. $194.98 \mathrm{mg} / \mathrm{dl}$ ), TG (121.16 vs. $126.18 \mathrm{mg} / \mathrm{dl}$ ), HDL (45.08 vs. 43.84 $\mathrm{mg} / \mathrm{dl})$, VLDL (24.23 vs. $25.24 \mathrm{mg} / \mathrm{dl})$ and LDL (122.8 vs. $125.9 \mathrm{mg} / \mathrm{dl}$ ) was not significantly different. Thus, there was no significant clinical difference between fasting and non fasting levels of total cholesterol, TG,
Comparison between laboratory findings of the lipid parameters in fasting and postprandial status in healthy young adults.

\begin{tabular}{cccc} 
Parameters & $\begin{array}{c}\text { Fasting } \\
{[\text { mean }( \pm \text { SD })]}\end{array}$ & $\begin{array}{c}\text { Postprandial } \\
{[\text { mean }( \pm \text { SD })]}\end{array}$ & P value \\
\hline TC $(\mathrm{mg} / \mathrm{dl})$ & $192.1( \pm 9.55)$ & $194.98( \pm 10.21)$ & $0.0407^{*}$ \\
TG $(\mathrm{mg} / \mathrm{dl})$ & $121.16( \pm 4.56)$ & $126.18( \pm 3.71)$ & $0.0001^{* *}$ \\
HDL $(\mathrm{mg} / \mathrm{dl})$ & $45.08( \pm 4.48)$ & $43.84( \pm 4.98)$ & 0.0656 \\
VLDL $(\mathrm{mg} / \mathrm{dl})$ & $24.23( \pm 0.91)$ & $25.24( \pm 0.74)$ & $0.0001^{* *}$ \\
LDL $(\mathrm{mg} / \mathrm{dl})$ & $122.8( \pm 10.78)$ & $125.9( \pm 10.6)$ & $0.0416^{*}$
\end{tabular}

TC- cholesterol; TG- triglyceride; HDL- high density lipoprotein; VLDL- very low-density lipoprotein; LDL-low density lipoprotein; TG- triglyceride, $P>0.05$ : not significant. $P<0.05$ : significant ${ }^{*}, P<0.001$ : Highly significant ${ }^{* *}$

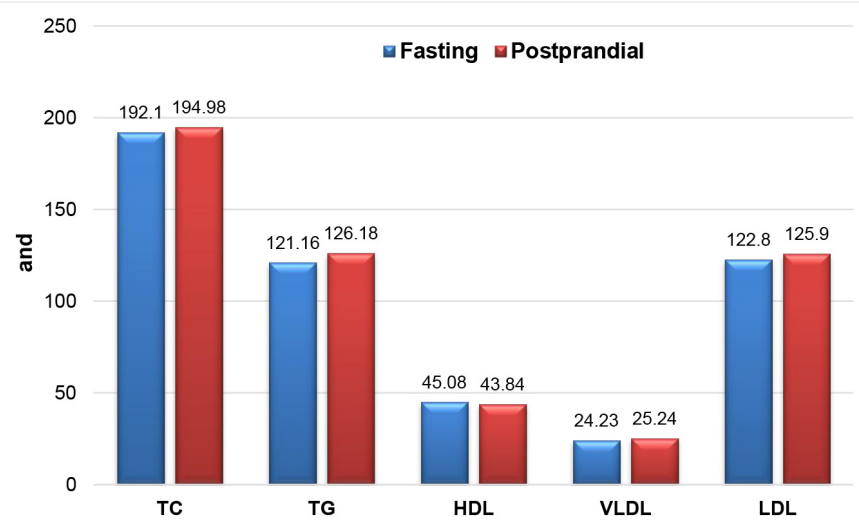

Comparison of Lipid parameters in fasting and postprandial statuses in healthy young adults.

HDL, VLDL and LDL. This change in levels of lipids, at most in response to normal food intake is minimal and unimportant.

Evidence suggests differences in cholesterol levels based on fasting versus not fasting are not clinically significant. In 2013, the American College of Cardiology and the American Heart Association released guidelines noting that non-fasting lipid tests can be used for assessing cardiovascular risk, but still recommended a fasting lipid panel prior to statin initiation. ${ }^{[3]}$ Anne Langsted et al. and Samia Mora et al. demonstrated that fasting lipid levels are not superior to non fasting levels for cardiovascular risk prediction. ${ }^{[4,5]}$

Since the 1970s, numerous reports from well-conducted, large, representative and mostly prospective studies with medium to long-term follow-up have consistently found that non-fasting lipids suffice for screening of cardiovascular disease risk. ${ }^{[4-8]}$ postprandial hypertriglyceridemia may play an important role in atherosclerosis. Objective To determine the association of triglyceride levels (fasting vs nonfasting).

Study by Langsted, A. and Nordestgaard, B. G. showed that postprandial reductions in HDL cholesterol observed in both populations were caused by hemodilution due to fluid intake. No statistically significant differences in postprandial apolipoprotein B concentrations were found. ${ }^{[9]} \mathrm{A}$ paradigm shift towards measuring postprandial lipid profile, as opposed to fasting lipids has occurred in recent decades. Some countries have already adopted nonfasting lipid testing (i.e. measured on a random blood sample irrespective of time since last meal) in routine practice, including Denmark in 2009, the UK in 2014, as well as Europe and Canada in 2016. 
Study by Sidhu D and Naugler C. showed that fasting times showed little association with lipid subclass levels in a community-based population, which suggests that fasting for routine lipid levels is largely unnecessary. ${ }^{[9-11]}$ Several large-scale, population-based studies and registries including children, women, men and patients with diabetes have now demonstrated that no clinically significant difference was found in diabetic or nondiabetic patients of fasting and nonfasting lipid profile..$^{[6,7,12-14]} 1166$ of whom developed cardiovascular events during 14 years of follow-up. Compared with fasting levels, total cholesterol, low-density lipoprotein cholesterol, High-Density Lipoprotein (HDL).

The advantages of a determining lipid profiles in a non-fasting blood sample are that patients who have not fasted do not have to make another appointment to have their blood drawn, By not requiring an overnight fast, the crowd of patients showing up in the morning for a blood test is lessened and physicians are spared from having to track down repeat tests. Laboratories won't be overwhelmed with people in the morning; patients can receive testing during a physician visit; and patients are likely to be more compliant with testing. Requiring fasting is also difficult for those with diabetes and for children. ${ }^{[9]}$ It is quite reasonable to suggest that lipid profile testing performed on samples collected in the nonfasting state at a random time convenient for the patient and the laboratory represents the way of the future. Arguments in support of this approach include the following: 1) most people are in the nonfasting state for most of the day, 2) this state may be a better reflection of the true metabolic state of a person, 3) nonfasting triglycerides possibly are better at predicting cardiovascular disease risk than fasting triglycerides and 4) nonfasting lipid profiles simplify blood sampling for patients, laboratories, general practitioners and hospital doctors alike. ${ }^{[14]}$ The study of White et al. is timely, as the current trend toward the use of nonfasting lipid profile testing has created an urgent need for evidence-based cutpoint values for the reporting and flagging of abnormal nonfasting triglycerides in laboratory reports. When non-fasting plasma triglyceride concentration is more than $440 \mathrm{mg} / \mathrm{dL}$ ( $>5 \mathrm{mmol} / \mathrm{L}$ ) consideration should be given to repeating the lipid profile in the fasting state. ${ }^{[15]}$

\section{Study limitations}

The limitation of our study was that the samples were obtained from a relatively small portion of population with normal lipid profile. We suggest further study should be done on larger population.

\section{CONCLUSION}

In this study we did not found any significant clinical difference between fasting and nonfasting levels of Total Cholesterol, Triglycerides, High density lipoprotein, Very low-density lipoprotein and Low-density lipoprotein. Thus, we can use the nonfasting blood samples to estimate lipid profile in follow-up the dyslipidemic patients. There is no need to make fasting lipid profile mandatory. This study suggests efforts should be made to simplify blood sampling by replacing fasting lipid profile with non-fasting lipid profile. It is necessary to determine cut-points of non-fasting lipid values. Life-threatening or extremely abnormal test results deserve special attention and reactions of the clinical biochemical laboratory.

\section{CONFLICT OF INTEREST}

The authors declare that there are no conflicts of interest.

\section{Source of Funds}

Nil.

\section{Ethical Clearance}

Institutional ethical committee, LAMGMC, Raigarh

Special thanks to Dean Dr. S. L. Adile and Department of Biochemistry.

\section{REFERENCES}

1. Abdel-aziza WF, Soltana GM, Ahmed AM. Comparison between fasting and nonfasting lipid profile in patients receiving treatment with statin therapy. Menoufia Med J. 2016;30(2):614-8.

2. Nordestgaard BG. A Test in Context: Lipid Profile, Fasting Versus Nonfasting. J Am Coll Cardiol. 2017;70(13):1637-46.

3. Farukhi Z, Mora S. Re-assessing the role of non-fasting lipids: a change in perspective. Ann Transl Med. 2016;4(21):431.

4. Langsted A, Freiberg JJ, Nordestgaard BG. Fasting and Nonfasting Lipid Levels: Influence of Normal Food Intake on Lipids, Lipoproteins, Apolipoproteins and Cardiovascular Risk Prediction. Circulation. 2018;118(20):2047-56. cited 2008.

5. Mora S, Rifai N, Buring JE, Ridker PM. Fasting Compared with Nonfasting Lipids and Apolipoproteins for Predicting Incident Cardiovascular Events. Circulation. 2008;118(10):993-1001.

6. Bansal S, Buring JE, Rifai N, Mora S, Sacks FM, Ridker PM. Fasting Compared with Nonfasting Triglycerides and Risk of Cardiovascular Events in Women. JAMA. 2007;298(3):309.

7. Doran B, Guo Y, Xu J, Weintraub H, Mora S, Maron DJ, et al. Prognostic Value of Fasting Versus Nonfasting Low-Density Lipoprotein Cholesterol Levels on Long-Term Mortality: Insight From the National Health and Nutrition Examination Survey III (NHANES-III). Circulation. 2014;130(7):546-53.

8. Nordestgaard BG, Langsted A, Mora S, Kolovou G, Baum H, Bruckert E, et al. Fasting is not routinely required for determination of a lipid profile: clinical and laboratory implications including flagging at desirable concentration cut-pointsa joint consensus statement from the European Atherosclerosis Society and European Federation of Clinical Chemistry and Laboratory Medicine. Eur Heart J. 2016;37(25):1944-58.

9. Langsted A, Nordestgaard BG. Nonfasting Lipids, Lipoproteins and Apolipoproteins in Individuals with and without Diabetes: 58434 Individuals from the Copenhagen General Population Study. Clin Chem. 2011;57(3):482-9.

10. Sidhu D, Naugler C. Fasting Time and Lipid Levels in a Community-Based Population. Arch Intern Med. 2012;172(22):1707.

11. Duggal A. Comparison of Fasting and Non Fasting Lipid Profile and Lipoprotein (a) in Healthy Adult Population. J Med Sci Clin Res. 2017;05(05):22070-7.

12. Weiss $R$, Harder M, Rowe J. The relationship between nonfasting and fasting lipid measurements in patients with or without type 2 diabetes mellitus receiving treatment with 3-hydroxy-3-methylglutaryl-coenzyme A reductase inhibitors. Clin Ther. 2003;25(5):1490-7.

13. Steiner MJ, Skinner AC, Perrin EM. Fasting Might Not Be Necessary Before Lipid Screening: A Nationally Representative Cross-sectional Study. Pediatrics. 2011;128(3):463-70.

14. Langsted A, Nordestgaard BG. Nonfasting Lipid Profiles: The Way of the Future. Clin Chem. 2015;61(9):1123-5.

15. Nordestgaard BG, Langsted A, Mora S, Kolovou G, Baum H, Bruckert E, et al Special Report Fasting Is Not Routinely Required for Determination of a Lipid Profile: Clinical and Laboratory Implications Including Flagging at Desirable Concentration Cutpoints-A Joint Consensus Statement from the European Atherosclerosis Society an. Clin Chem. 2016;62:(7):930-46. 